\title{
Retos éticos para los administradores en salud en la época contemporánea
}

\author{
Ethical Challenges for Health Service Managers in contemporary times
}

\author{
Retos éticos para os administradores de serviços de saúde \\ na época contemporânea
}

\author{
Mónica Lopera Medina \\ 1 Doctora en Salud Pública. Universidad de Antioquia. monica.lopera@udea.edu.co. oRCID: https://orcid.org/0000-0003-0144-057X
}

Recibido: 25/05/2020. Aprobado.09/06/2021. Publicado: 30/11/2021

Lopera-Medina M. Retos éticos para los administradores en salud en la época contemporánea. Rev. Fac. Nac. Salud Pública. 2022;40(1):e341003. DoI: https://doi.org/10.17533/udea.rfnsp.e341003

\section{Resumen}

El administrador en salud se ve permanentemente retado por la compleja función que se le atribuye en la gestión de los procesos organizacionales, en contextos sociales complejos. En este ensayo se presenta una reflexión sobre los retos éticos con los que se encuentran actualmente los administradores en salud, derivados de los contextos socioeconómicos de la época contemporánea, así como los relativos al ejercicio de la administración en salud en sus áreas funcionales: procesos administrativos, gestión del talento humano, gestión financiera, dirección de los procesos asistenciales e investigación en salud. La reflexión ética, a partir de diferentes perspectivas, es un camino necesario para encontrar respuestas a las contradicciones morales y discernir arbitrajes complejos del ser (ética ontológica) y del quehacer (ética deontológica), sin perder de vista que la finalidad de la administración en salud es mejorar la salud y la calidad de vida de las poblaciones.

--Palabras clave: Administración en salud, ética profesional, ética en administración en salud, teoría de la ética. 


\begin{abstract}
Health administrators are constantly challenged by their role in the management of organizational processes in complex social contexts. This essay presents a reflection on the ethical challenges that face health administrators, originated in the socioeconomic contexts of the contemporary era, as well as those related to the exercise of health administration in its functional areas: administrative processes, human talent management, financial management, management of care
\end{abstract}

processes and health research. The ethical reflection, from different perspectives, is a necessary path to find answers to moral contradictions and to discern the complex arbitrations of being (ontology) and, of duty (deontology), without losing focus on the purpose of health administration which is to improve health and quality of life of populations.

-Keywords: Health administration, professional ethics, ethics in health administration, theory of ethics.

\section{Resumo}

O administrador em saúde é permanentemente desafiado pela complexa função que se lhe atribui na gestão dos processos organizacionais, em contextos sociais complexos. Neste ensaio, apresenta-se uma reflexão sobre os desafios éticos com os quais se deparam os administradores em saúde atualmente, derivados dos contextos socioeconômicos da época contemporânea, assim como aos relacionados ao exercício da administração em saúde em suas áreas funcionais: processos administrativos, gestão do talento humano, gestão financeira, direção dos processos assistenciais e pesquisa em saúde. A reflexão ética, partindo de diferentes perspectivas, é um caminho necessário para encontrar respostas às contradições morais e discernir arbitragens complexas do ser (ética ontológica) e do que fazer (ética deontológica), sem perder de vista que a finalidade da administração em saúde é melhorar a saúde e a qualidade de vida das populações.

-Palavras-chave: Administração em saúde; Ética profissional; Ética em administração em saúde; Teoria da Ética

\section{Introducción}

En la literatura nacional e internacional, el tema de "la ética en administración en salud" es escaso. La búsqueda en la base de datos Centro Latinoamericano y del Caribe de Información en Ciencias de la Salud (Bireme), utilizando los términos en español "Ética" AND "Administración" AND "Salud", arrojó una sola publicación [1], y en inglés, "Sanitary Management" AND "Ethics", ninguna. La consulta en PubMed $\AA$, mediante los términos "Ethics" AND "Healthcare management", dio como resultado un solo artículo, publicado en 1997 [2], mientras "Ethics" and "Health service management" arrojó solo dos artículos, uno de 1992 y otro de 2008, ninguno de los dos asociados con el propósito de este artículo.

Ante esta escasa literatura, se siguió una revisión intencionada, basada en la praxis profesional de la administración en salud, con el fin de presentar una reflexión sobre los retos éticos con los que se encuentran actualmente los administradores en salud, derivados de los contextos socioeconómicos de la época contemporánea, así como los relativos al ejercicio de la administración en salud en sus áreas funcionales: procesos administrativos, gestión del talento humano, gestión financiera, dirección de los procesos asistenciales e investigación en salud.
Para lograr ese objetivo, en la primera parte de este ensayo se describen elementos de la ética deontológica y su relación con la administración; luego, se enuncia la misión del administrador de servicios de salud, después se exponen el ejercicio ético del administrador y las perspectivas teóricas de la ética, para, posteriormente, enunciar los principales retos a los que se enfrenta el administrador, según los contextos y las cinco áreas funcionales de las organizaciones, bien sean estas de carácter social o instituciones propiamente de salud, que pueden producir conflictos entre los diferentes valores y, por lo tanto, ameritan una reflexión ética.

\section{Ética profesional y administración de los servicios de salud}

La ética profesional, también llamada "ética deontológica", es el conjunto de normas de conducta ideal, emitidas por las asociaciones de profesionales para aquellos que integran una profesión en particular; por lo tanto, la ética profesional es específica a su ejercicio [3]. No obstante, dichas normas de conducta no pueden verse al 
margen de las cuestiones ontológicas (del ser), profundamente delineadas por los hábitats natural y construido que conforman el ethos vital, ${ }^{*}$ ni de la trama simbólica que concede identidad a los grupos humanos [4]. Esto significa que la ética profesional está ligada a los aprendizajes éticos primarios (los aprendidos desde etapas tempranas de la vida) y a aquellos hábitos que constituyen el carácter moral y, por ende, determinan el comportamiento que guía la conducta constante en cada esfera de la vida $[5,6]$.

A pesar de la incidencia del ethos vital y de la identidad de los grupos en el carácter moral, tanto los conocimientos como las habilidades se pueden formar a lo largo de la vida y, por esta razón, es necesario reflexionar, fortalecer y desarrollar la ética profesional [6]. Así, la reflexión permanente sobre la construcción del carácter moral del administrador en salud es un propósito, no solo deseable, sino también mandatorio para el buen ejercicio de su profesión.

\section{La misión del administrador de servicios de salud: lo} que se administra

"Administrar" significa liderar y gestionar. Pero esta función no se desarrolla en abstracto. El administrador de servicios de salud administra instituciones del sistema de salud y se involucra en procesos sociales e institucionales que tienen como fin promover la salud, prevenir que los individuos y la sociedad enfermen, y disponer los recursos para la recuperación de la salud, o incluso, los servicios que aporten a una muerte digna. El administrador hace uso de recursos humanos, técnicos, tecnológicos y administrativos que permitan proveer servicios tendientes a prevenir, tratar, curar, paliar y mitigar la enfermedad, la discapacidad, el sufrimiento y el dolor en quienes ya se encuentran afectados.

La administración de servicios de salud tiene efectos bidireccionales: influye en los aspectos individuales, en la comunidad, en las organizaciones sociales y sanitarias, en la economía, en el desarrollo social y humano, y en el sistema político, pero también es afectada por ellos, lo que significa que dichos procesos determinan la forma como se administra.

La práctica específica del administrador en salud, sea esta de carácter social o institucional, debería implicar la adhesión a valores como el respeto, la solidaridad y la honestidad, entre otros, a fin de que con dicha práctica se procuren el bienestar y la protección del derecho a la salud de la población, la sostenibilidad ambiental y la responsabilidad social. La administración en salud obliga a los profesionales a gestionar procesos de salud con calidad técnica y humana, aun en contextos económicos que los presionen a gestionar los servicios con criterios

El ethos vital son los valores morales que hacen posible la supervivencia exitosa de nuestra especie y del hábitat. economicistas, como es común en sistemas de salud segmentados y privados.

La administración en salud, independiente de si se trata de procesos sociales o institucionales, incluye al menos cinco funciones básicas: 1) administrar, gerenciar y tomar decisiones acerca del conjunto de las organización y, en consecuencia, definir su marco ético; 2) dirigir el talento humano; 3) coordinar los procesos institucionales de financiamiento y administración económica; 4) velar por la prestación eficaz y eficiente de los servicios de salud, tanto básicos como aquellos que incorporan tecnologías especiales, y 5) velar porque los desarrollos científicos e investigativos se lleven a cabo bajo condiciones éticas apropiadas.

\section{La ética y el ejercicio profesional del administrador de servicios de salud}

El ejercicio ético del administrador en salud debe estar dirigido principalmente a obtener mejores resultados en salud, pero, a su vez, a crear valores compartidos, que generen congruencia, confianza y lealtad de los actores con quienes interactúa. En el ejercicio de su profesión, el administrador se ve abocado a dirimir los múltiples conflictos éticos que emergen como consecuencia de las situaciones que resultan de valores sociales contrapuestos de los diferentes actores sociales e institucionales.

La ética facilita la planeación, estimula el reconocimiento del valor del personal colaborador y, por lo tanto, constituye una forma de manejar las crisis y prevenir la reglamentación opresiva. Una perspectiva más pragmática, pero debatible, se encuentra en Bowie, quien plantea la eticidad como forma de seguro para prevenir costosos litigios o intervenciones del Estado en instituciones públicas y privadas, y para mejorar la eficacia e incluso la rentabilidad [7].

Diversas asociaciones de médicos en Estados Unidos y Europa han propuesto los principios fundamentales y las responsabilidades profesionales del médico, que se enuncian a continuación por su compatibilidad con el ejercicio de la administración en salud, y que han sido complementados en este escrito, puesto que su quehacer trasciende la administración de lo asistencial.

De acuerdo con estas organizaciones, los principios fundamentales que deben guiar su acción son la primacía del bienestar del paciente, así como el trato equitativo, digno y respetuoso. Como responsabilidades profesionales, se plantean la competencia profesional; la honestidad; la salvaguarda de la confidencialidad; el mantenimiento de relaciones correctas con los pacientes y con otros (prestadores, proveedores); la justa distribución de los recursos; el cuidado en el manejo de conflictos de interés, y la promoción de actitudes, valores y principios que deben aplicarse con observancia de los derechos y en respeto de la dignidad humana y la justicia social [8-10]. 
Estos principios parecen razonables, aunque son las circunstancias relacionadas con los contextos y las situaciones cotidianas las que ponen en tensiones al administrador y le retan para tomar decisiones éticas. Por supuesto, lo que se considera ético está marcado por los valores individuales, deontológicos, pero especialmente por las perspectivas u orientaciones de lo que estima el bien hacer, de acuerdo con las perspectivas teóricas que se acojan y que se enuncian en el siguiente apartado.

\section{Perspectivas teóricas de la ética: la noción del bien hacer}

Aunque la noción de ética remite al bien hacer, lo correcto o el bien moral, el significado de ello varía en función de muchos factores: la evaluación previa de los principios personales, los valores institucionales, el análisis de la situación y los fenómenos conexos (casuística), así como por las bases filosóficas y las herramientas que cada perspectiva teórica plantea.

A continuación se describen los fundamentos centrales de algunas perspectivas teóricas de la ética. Estas perspectivas proponen una orientación de lo que constituye lo correcto o el bien hacer; por lo tanto, el administrador en salud puede adherirse a una o varias de ellas, para fundamentar la toma de decisiones en situaciones que le planteen divergencias entre valores o principios:

- Ética deontológica kantiana. También llamada "ética normativa". Defiende los procedimientos racionales, la universalidad y el imperativo categórico. Immanuel Kant insta a tratar a los demás como fines y no como medios, perspectiva que constituye una base para la doctrina de las virtudes [11].

- Ética principalista de Beauchamp y Childress. Insta al sujeto a actuar bajo un marco amplio de cuatro principios morales: la beneficencia, la no maleficencia, la justicia y la autonomía [12].

- Ética de la virtud. Gestada por Aristóteles y retomada en una versión neoaristotélica por Alasdair MacIntyre y por Marta Nusbaum, se enfoca en la pregunta por la felicidad, por las virtudes morales, cívicas y políticas; por la educación de los sentimientos morales y la consolidación del carácter [13], y por la justicia como parámetro de la felicidad, lograda a través de la prudencia y la virtud [14].

- Consecuencialismo. Esta perspectiva plantea que las situaciones producidas por una acción se juzgarán de acuerdo con las consecuencias, prescindiendo de las intenciones de quien realiza la acción. En este caso, lo correcto es la búsqueda del mayor bien, propio o de los demás [15].

- Perspectiva basada en los derechos humanos. En las últimas décadas, la ética se ha nutrido de los aportes relacionados con los derechos civiles, la justicia social, los movimientos antidiscriminación y antiexclusión, la lucha por los derechos humanos, el derecho a la salud y los derechos al acceso equitativo a los servicios de salud [16].

Aunque estas perspectivas son aspiraciones que responden a ideales de sociedad, la coacción, el constreñimiento institucional y social de las corrientes neoliberales hegemónicas y aquellas propias de las dinámicas contextuales pueden generar barreras concretas para su realización.

\section{Retos éticos para el ejercicio de los administradores de salud, según los contextos y las áreas funcionales}

Por el alcance del campo disciplinar y los contextos en los que se desarrolla, en la actualidad los administradores afrontan retos éticos que trascienden los problemas de la bioética tradicional, para ubicarse en la compleja trama de los procesos que se producen en el proceso dialéctico entre las necesidades sociosanitarias y la respuesta social, así como en las configuraciones y relaciones entre los actores: profesionales administrativos y de la salud, proveedores, pacientes, y otras organizaciones políticas, civiles y económicas.

De esta manera, en este apartado se reflexiona acerca de la incidencia de las situaciones contextuales en los retos éticos que enfrenta el administrador en salud, así como sobre los retos éticos que afronta en la gestión de las áreas funcionales.

Incidencia de los contextos en los retos éticos que afronta el administrador de servicios de salud

La administración en salud no se desarrolla en abstracto. Por el contrario, los contextos sociales adversos hacen que el ejercicio de la administración de la salud sea más o menos complejo.

La complejidad del contexto impone retos al administrador para la toma de decisiones éticas. Berlinguer ha sintetizado los problemas sociosanitarios contextuales a los que se deben enfrentar los profesionales de la salud y, por extensión, los administradores en salud: profundas inequidades sociales y sanitarias, diferencias entre necesidades y derechos, privatización y mercantilización de servicios, dilemas entre soberanía y sometimiento, grupos de presión y corrupción, límites entre el paternalismo y la autonomía, entre otros [16].

Por su parte, Galindo señala algunos "macrodesórdenes", que constituyen retos contextuales a los que también se ven abocados los profesionales de la administración de servicios de salud: el crecimiento demográfico, los desarrollos tecnológicos, los problemas ambientales, la destrucción de los recursos naturales [4]. 
Hay que notar que el papel del administrador en salud se desarrolla en poblaciones heterogéneas, debido a su condición socioeconómica, su ubicación geográfica, su género e identidad sexual. Esta diversidad poblacional y en especial cuando se trata de situaciones de alta vulnerabilidad, aumenta los retos éticos para la toma de decisiones del administrador [17].

Los cambios sociopolíticos, así como los acontecidos en la economía global, han transformado la concepción, la organización, la financiación y la gestión de los sistemas de salud. Los sistemas de salud contemporáneos, en países de ingresos medios y bajos, fueron predominantemente instaurados con lógicas mercantilistas, orientados por los enfoques economicistas [18], y hoy retomados bajo la propuesta de la atención gerenciada (New Management). Estas lógicas reprochan el carácter público de la salud, asimilan las organizaciones prestadoras de servicios de salud a empresas con carácter lucrativo, que no se ajustan a la vocación de las instituciones que se administran, que es precisamente el mantenimiento de la salud y el bienestar. En estos casos, se antepone la rentabilidad, se prioriza la productividad y la ganancia y, en consecuencia, se constriñe al administrador en salud a la toma de decisiones que pueden resultar desfavorables a los fines primarios que debería perseguir [19].
Algunos de los problemas enunciados ocasionan, a su vez, problemas éticos notables, en la medida en que los valores que subyacen se sustentan en la dominación y la avaricia, en lugar de la solidaridad y el reconocimiento del otro. Dichos valores son contrarios a los valores sociales requeridos para lograr que la salud sea un bien social. No obstante, mientras la solución esté a su alcance, el reto ético del administrador consiste en proteger a las poblaciones, con especial énfasis en aquellas más vulnerables, mientras se administran los recursos de manera eficaz y eficiente. Cuando existe pugna entre actores, el administrador debe sentar posición frente a los individuos o grupos que favorece o perjudica con su accionar.

En presencia de los complejos problemas sociosanitarios y macrodesórdenes, el administrador en salud debe ocuparse de al menos cuatro ámbitos éticos propuestos por Pieper: la ética social, la ética económica, la ética científica y la ética ecológica [20]. Estos ámbitos se solapan en la práctica social concreta.

En la Tabla 1 se proponen algunos retos éticos que derivan de contextos adversos de la época contemporánea, especificados según los cuatro ámbitos.

Tabla 1. Problemas contextuales que afectan el ejercicio profesional del administrador en salud

\begin{tabular}{|c|c|}
\hline Problema contextual & Retos éticos para el administrador en salud \\
\hline $\begin{array}{l}\text { Problemas sociosanitarios y } \\
\text { ambientales } \\
\text { (ética social) } \\
\text { Inequidades sociales y sanitarias } \\
\text { (ética social) } \\
\text { Problemas ambientales y } \\
\text { destrucción de los recursos } \\
\text { naturales (ética ecológica) }\end{array}$ & $\begin{array}{l}\text { Un gran número de la población está sumido en situaciones de pobreza e inseguridad } \\
\text { ambiental. La enfermedad se expresa de manera diferencial según las condiciones } \\
\text { socioeconómicas y ambientales, y afecta predominantemente a los más pobres. } \\
\text { Esta situación pone en tensión al administrador de servicios, puesto que debería estar } \\
\text { abocado a contribuir a la disminución de inequidades sociales y sanitarias y, sin embargo, } \\
\text { queda circunscrito a la prestación de servicios en condiciones de mercado. } \\
\text { Por otra parte, cualquier decisión que tome en materia de infraestructura o servicios } \\
\text { afectará al ambiente y, por lo tanto, la jerarquía de valores predominantes lo pueden poner } \\
\text { en situaciones problemáticas o dilemáticas }\end{array}$ \\
\hline $\begin{array}{l}\text { Los desarrollos tecnológicos } \\
\text { (ética científica) }\end{array}$ & $\begin{array}{l}\text { La tecnología puede estar disponible, pero no necesariamente ser asequible para toda la } \\
\text { población. } \\
\text { La adquisición de tecnologías lleva implícito un costo de oportunidad, que frecuentemente } \\
\text { afecta a las poblaciones más vulnerables }\end{array}$ \\
\hline $\begin{array}{l}\text { Poblaciones heterogéneas } \\
\text { (ética social) }\end{array}$ & $\begin{array}{l}\text { La heterogeneidad poblacional se produce debido a características individuales, sociales o } \\
\text { culturales. El administrador se encuentra ante problemas o dilemas éticos cuando en aras } \\
\text { de la igualdad abandona la equidad o el enfoque diferencial }\end{array}$ \\
\hline $\begin{array}{l}\text { Transformación de los } \\
\text { sistemas de salud con lógicas } \\
\text { mercantilistas, privatización y } \\
\text { mercantilización de servicio } \\
\text { (ética económica) }\end{array}$ & $\begin{array}{l}\text { Transformación del carácter público de la salud por el carácter lucrativo. } \\
\text { Las prácticas anteponen la rentabilidad, la productividad y la ganancia. } \\
\text { El problema ético consiste en que la atención puede quedar supeditada a la capacidad } \\
\text { adquisitiva de los individuos y sus familias. Esto implica que no necesariamente se } \\
\text { resolverán las necesidades de salud de la población más pobre y vulnerable }\end{array}$ \\
\hline $\begin{array}{l}\text { Grupos de presión y corrupción } \\
\text { (ética social) }\end{array}$ & $\begin{array}{l}\text { En cualquier ámbito en el que el administrador en salud se desempeñe, puede verse } \\
\text { sometido a los intereses de grupos de presión, que harán que se tomen decisiones aun en } \\
\text { detrimento del fin que persigue. Esto puede poner en cuestión su integridad y sus principios }\end{array}$ \\
\hline $\begin{array}{l}\text { Límites entre el paternalismo y la } \\
\text { autonomía } \\
\text { (ética social) }\end{array}$ & $\begin{array}{l}\text { Los administradores se encuentran inmersos en situaciones que lo dirigen a realizar } \\
\text { prácticas paternalistas que rompen con la autonomía de los pacientes. Esto puede ser } \\
\text { evidente en la definición de procedimientos administrativos e itinerarios para acceder a sus } \\
\text { derechos, la instalación de infraestructura o servicios (sociales o de salud), en contra de los } \\
\text { intereses de los usuarios o los pacientes }\end{array}$ \\
\hline
\end{tabular}




\section{Retos éticos en la gestión de las áreas funcionales que enfrenta el administrador en salud}

En la Tabla 2 se describen los retos éticos a las que se ve abocado el administrador de salud en las cinco áreas funcionales que constituyen su misión: proceso administrativo, gerencia y toma de decisiones, dirección del talento humano, área financiera y contable, prestación de servicios e investigación en salud [21].

Tabla 2. Retos éticos en las cinco áreas funcionales de las instituciones

\begin{tabular}{|c|c|}
\hline Áreas funcionales & Retos \\
\hline \multirow{6}{*}{$\begin{array}{l}\text { Proceso } \\
\text { administrativo, } \\
\text { gerencia y toma de } \\
\text { decisiones }\end{array}$} & $\begin{array}{l}\text { Problemas y dilemas de carácter ontológico (del ser) } \\
\text { Problemas prácticos, en función de la posición que se ocupa y de la naturaleza de los problemas }\end{array}$ \\
\hline & $\begin{array}{l}\text { Problemas éticos en las organizaciones: } \\
\text { 1. Conflictos con otros } \\
\text { Diferencia de valores y principios entre los clientes, los proveedores, los empleados, los competidores, las } \\
\text { autoridades reguladoras y gubernamentales, los superiores y la comunidad }\end{array}$ \\
\hline & $\begin{array}{l}\text { 2. Problemas con el capital de aportación } \\
\text { Definición del sueldo de los ejecutivos } \\
\text { Establecimiento del precio de los productos }\end{array}$ \\
\hline & $\begin{array}{l}\text { 3. Problemas asociados con los derechos } \\
\text { Definición y continuidad de los procesos corporativos } \\
\text { Desprotección de los derechos laborales } \\
\text { Definición de exámenes médicos } \\
\text { Determinación de acciones que ocasionen la invasión a la privacidad } \\
\text { Permisividad o prácticas de acoso (sexual, laboral, discriminación racial, sanitaria) } \\
\text { Desprotección al usuario, al paciente o al cliente (atención subóptima, fallos de acceso, calidad u } \\
\text { oportunidad) } \\
\text { Problemas del uso de los avances informáticos y su relación con el secreto médico }\end{array}$ \\
\hline & $\begin{array}{l}\text { 4. Problemas con la honestidad } \\
\text { Problemas relacionados con la producción del servicio que resulte en afectaciones a la calidad } \\
\text { Decisiones permeadas por conflictos de interés, o corrupción y cooptación política } \\
\text { Procedimientos que violen o impidan la seguridad de expedientes } \\
\text { Recibir o proveer regalos o sobornos para cambiar el rumbo de la acción } \\
\text { Realizar pagos no autorizados } \\
\text { Determinar contenido engañoso de la publicidad, que lleve a errores al paciente }\end{array}$ \\
\hline & $\begin{array}{l}\text { 5. Problemas asociados con el ejercicio del poder } \\
\text { Connivencia en los precios de los servicios y en las formas para establecerlos } \\
\text { Despidos } \\
\text { Problemas en las comunicaciones } \\
\text { Problemas asociados a la ejecución de contratos con inversionistas } \\
\text { Invasión a la privacidad } \\
\text { Injusticia en la remuneración de los empleados y en las relaciones comerciales } \\
\text { La tergiversación de los mercados } \\
\text { Despidos masivos, entre otros } \\
\text { La concurrencia desleal }\end{array}$ \\
\hline $\begin{array}{l}\text { Dirección del } \\
\text { talento humano } \\
\text { (Sección B) }\end{array}$ & $\begin{array}{l}\text { Manejo inadecuado de los incidentes acontecidos en el lugar de trabajo } \\
\text { Problemas asociados con la experiencia del trabajo (relaciones, administración del lugar de trabajo) } \\
\text { Dilema entre profesionalismo y ocupación }\end{array}$ \\
\hline $\begin{array}{l}\text { Área financiera y } \\
\text { contable } \\
\text { (Sección C) }\end{array}$ & $\begin{array}{l}\text { Problemas referidos a la priorización y la asignación del gasto } \\
\text { Relaciones contractuales y mercadeo indebidos } \\
\text { Problemas relacionados con la admisión hospitalaria, la transferencia de pacientes, el alta hospitalaria* y el } \\
\text { cobro de las facturas } \\
\text { Costos y formas de cobros e incentivos } \\
\text { Sobreutilización y subutilización de servicios de salud } \\
\text { Servicios independientes, provistos por múltiples organizaciones que efectúan convenios de referencia } \\
\text { recíproca en detrimento del mejor interés para el paciente } \\
\text { Autorreferencia de servicios innecesarios dentro de la misma organización, pero que factura separadamente } \\
\text { Convenios de referencia recíproca } \\
\text { Dimensión social y de interés público, en contraposición a estrategias para beneficiar los intereses privados }\end{array}$ \\
\hline
\end{tabular}




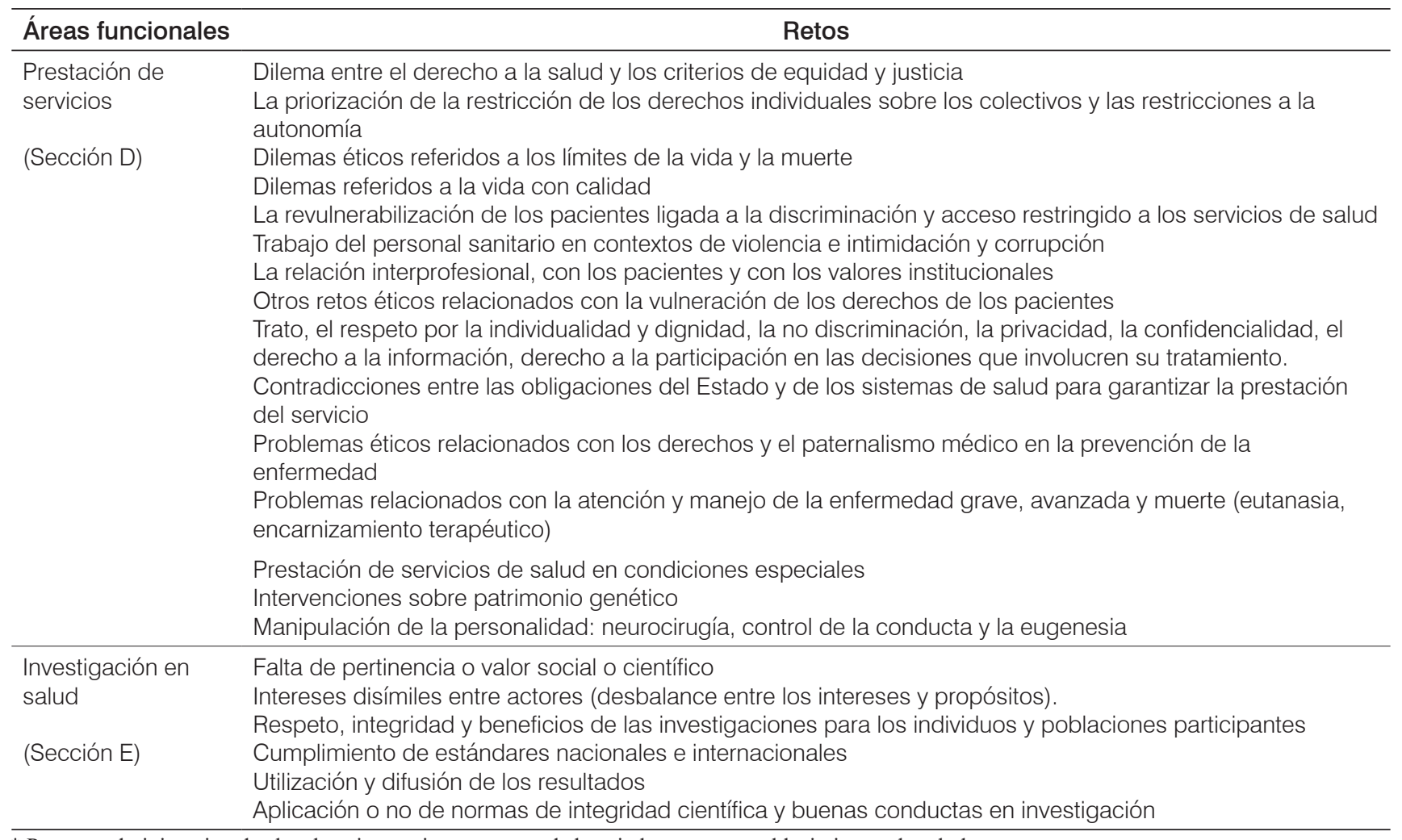

* Proceso administrativo de alta al paciente, vivo o muerto, de hospitales u otros establecimientos de salud.

Fuente: Elaboración propia.

\section{Proceso administrativo, gerencia y toma de decisiones}

El administrador debe dirigir todas las áreas de la organización de manera eficaz y eficiente. Para ello, debe definir los valores que la guían e implementar métodos, estrategias y herramientas que hagan posible que cada área se desarrolle de la mejor manera. Adicionalmente, los administradores, como agentes morales, tienen deberes básicos con los demás miembros de la sociedad, de tal forma que las organizaciones, aunque deban manejarse con criterio de eficiencia y acatamiento a las leyes, están obligadas también a ser buenas ciudadanas corporativas, y esto significa no solo obtener su beneficio, sino, además, aquel que la organización pueda retribuirle a la sociedad. ${ }^{\dagger}$

En la ética organizacional (Bussiness ethics) están implicadas las normas y los valores de los individuos, y de los grupos sociales de los que hacen parte. Las obligaciones morales del administrador en salud incluyen velar por la solidaridad, propender por la justicia social, preservar la libertad y la autonomía moral que lleva a cada individuo a buscar su propio bien y el de los demás,

$\dagger \quad$ Según Gómez Begoña, el término "ciudadano corporativo" se originó en los años ochenta y noventa para denotar que las responsabilidades sociales son propias de la empresa [22]. así como procurar la igualdad y la justa oportunidad para los miembros de la sociedad $[23,24]$.

En la práctica cotidiana, el administrador de servicios de salud se enfrenta a problemas y dilemas de carácter ontológico (del ser) o práctico, en función de la posición que se ocupa y de la naturaleza de los problemas organizacionales, ocupacionales, sociales y globales. Todas las acciones asociadas a la planeación, la gestión y la organización de los servicios de salud están imbuidas de contenido ético, esto es, involucran problemas, dilemas u oportunidades en donde existe discrepancia entre lo deseable (ética normativa) y lo que se concreta (ética descriptiva). Dichas discrepancias pueden producirse entre la ética personal y los intereses institucionales, así como con los valores admitidos socialmente [25].

Según Ferrell y Fraederich (citados por Swanson [24]), las cuestiones éticas obligan a elegir entre una o varias opciones, que pasan por el filtro de lo bueno, lo malo, lo deseable o indeseable, lo justo o injusto. Los problemas y dilemas obligan al administrador a tomar decisiones que distan de ser procesos meramente racionales. Estas decisiones están marcadas por las diferencias individuales, por la razón, las emociones, los contextos, la acción comunicativa, los factores asociados con el problema, la conciencia y el juicio 
moral, e incluso las normas técnicas, sociales, religiosas y civiles, entre otros $(3,26,27)$.

Vittel, Festervan y The Conference Board (citados por Bowie [7]) han descrito al menos cinco tipos de problemas éticos en las organizaciones, relacionados con: 1) los conflictos con otros, 2) con el capital de aportación, 3) con los derechos, 4) con la honestidad (o falta de esta) y 5) con el ejercicio del poder. Los conflictos con otros aluden a las diferencias entre los administradores y los grupos con los que se establecen vínculos. Los problemas asociados con el capital de aportación involucran las decisiones financieras de la empresa, tanto de los socios como de los precios que se ofrecen al público. Los problemas relacionados con los derechos incluyen, principalmente, los procesos corporativos; los de honestidad están vinculados a prácticas que vulneran la transparencia y la confianza, y los problemas inherentes al ejercicio del poder, con todo aquello que responde a prácticas jerárquicas malsanas [7].

Gélinier ha llamado la atención sobre otros problemas éticos emergentes en los contextos organizacionales contemporáneos, como las comunicaciones, la corrupción, la protección al consumidor, las cuestiones ambientales, el justo uso del dinero que se ubica en la remuneración de los empleados y en las relaciones comerciales [28]. Klebe ha descrito un conjunto de prácticas poco éticas en las organizaciones, relacionadas con la vulneración a la propiedad, la agresión personal, y las aberraciones respecto a la producción y a las políticas [29]. Una síntesis de los retos éticos relacionados con los proceso administrativos y gerenciales se puede observar en la Sección A de la Tabla 2.

Desde la década de los noventa, las empresas prestadoras de servicios de salud en el mundo han instaurado mecanismos normativos para evitar las faltas a la conducta y los actos ilegales. Estas prácticas están ligadas a la designación de responsables de la ética en las instituciones, usualmente vinculando a funcionarios con capacidad jurídica, con lo que se crea un interés por la ética en las organizaciones. Otros mecanismos se relacionan con la redacción de cartas éticas y principios fundamentales en el conjunto de la organización, cuyo elemento central es la ética personal y reconocida de los dirigentes, concretada en modos de elección, perfeccionamiento, comportamientos cotidianos, formación en la ética para los miembros y acciones formalizadas $[1,28]$.

\section{Dirección del talento humano}

De acuerdo con Ciulla, existe muy poca literatura sobre las consideraciones éticas referentes al trabajo como experiencia humana. Estos asuntos no solo tratan de los incidentes acontecidos en el lugar de trabajo, sino también de cuestiones esenciales de la experiencia del trabajo: las relaciones, la forma de administrar el lugar de trabajo y las afectaciones del mismo sobre la vida de las personas [30].

La concreción de los derechos laborales deviene del concepto que sobre ellos la sociedad acoja, y la racionalización que esta haga, y aquí se pueden describir al menos dos posturas: la primera, con dos líneas, una donde se reconocen derechos recíprocos entre el empleado y el empleador, y otra, más de tipo contractual, de tradición estadounidense, basada en el compromiso de transacciones de beneficio mutuo. La segunda se concreta en un modelo más reciente de la ética organizacional, según la cual los grupos que la conforman tienen intereses en la organización. Este abordaje resulta debatible, por cuanto oculta las relaciones de poder en la época neoliberal [3]. Estas perspectivas de la relación entre empleado y empleador producen distintas reivindicaciones de derechos y obligaciones [30].

En los procesos de la gestión del talento humano y los derechos, Duska ha descrito algunos de los elementos éticos que median las relaciones entre los trabajadores y los empleadores, relacionados con las divergencias entre el profesionalismo y la ocupación, los incidentes acontecidos en el lugar de trabajo y los problemas asociados con la experiencia del trabajo [31]) (véase Sección B, Tabla 2).

Aspectos éticos referentes al área funcional financiera y contable

Las finanzas, la contabilidad, la administración, el presupuesto, la auditoría y otras ciencias económicas son herramientas de interés público para la toma de decisiones, independiente del ámbito en el que se ejerza. El desarrollo de las prácticas en estas_disciplinas no ha carecido de escándalos, por actuaciones que se desarrollan en los límites de la legalidad, o bien resultan expresamente ilegales.

Las decisiones en la gestión financiera, como práctica social trascendente, están permanentemente sometidas a los retos éticos derivados de los conflictos en valores, intenciones, actuaciones y presiones de al menos tres actores que interactúan: 1) el colectivo empresarial y los agentes relacionados, como los profesionales contables y de la auditoría; 2) el Estado, representado en el poder público supervisor y regulador [32], y 3) la comunidad. El administrador debe estar presto a efectuar la debida rendición de cuentas, facilitando la auténtica participación social [33]. Los retos éticos en el área financiera y contable se relacionan con la priorización y la asignación del gasto, los contratos, el mercadeo, la admisión hospitalaria, los acuerdos intra e interinstitucionales y los costos, entre otros (véase Sección C de la Tabla 2.)

Schyve [34] puso de relieve varios de los elementos éticos que interfieren en la ética organizacional de los servicios de salud, relacionados con los costos y las 
formas de cobro por los servicios que promueven, dado que cada decisión produce incentivos deseables e indeseables a los actores. Algunos de los incentivos pueden poner en riesgo la calidad de la atención, la relación entre médico y paciente, e incluso el interés mismo del paciente.

La ética en el ejercicio de esta función no debería pasar por interpretar las normas y la información técnica de manera neutral y acrítica, sino por entender y acoger su fundamento y finalidad, al situarla en su cometido, dimensión social e interés público, al tiempo que preservar el sentido de la calidad y de lo público [30].

\section{Prestación de servicios}

Para evitar que los procesos financieros interfirieran en la ética de las decisiones misionales para la prestación de servicios de salud, en 2005, la Comisión Conjunta en Acreditación de las Organizaciones de Salud (Join Comission on Accreditation in Healthcare Organizations, JCAHC) estableció los estándares internacionales de acreditación en ética empresarial en salud, en las áreas de cuidado ambulatorio, cuidado en el hogar, cuidado hospitalario, comportamiento, redes de servicio, cuidado de largo plazo, laboratorios y patología [34]. Estos estándares fueron explicitados para asegurar que la integridad de las decisiones clínicas fuera protegida de las presiones financieras y que la organización prestadora de servicios de salud condujera su organización de manera apropiada [20]. Estas aspiraciones son compatibles con aquellas derivadas de las políticas que protegen los derechos de los pacientes, emanadas también de la JCAHC [34].

En la perspectiva institucional, que involucra las decisiones por acción u omisión, se especifican las obligaciones del Estado y de los sistemas de salud para garantizar las condiciones de prestación y el acceso a los servicios de salud, pero también la garantía del derecho a la salud desde una perspectiva más amplia. Estos derechos están contemplados en la Declaración Universal de Derechos Humanos, el Pacto de Derechos Económicos, Sociales y Culturales [35] y la Declaración Universal de Bioética y Derechos Humanos [36].

Los administradores en salud deben tener presente el dilema referido a la protección del derecho a la salud respecto al uso eficiente de los recursos. Uno de los principales problemas éticos en las decisiones médicas, según la postura utilitarista de la eficiencia máxima, es que, en la priorización y la asignación del gasto, las necesidades particulares de pacientes con enfermedades graves e infrecuentes deben ser dejadas de lado, para dar prioridad a enfermedades frecuentes, lo que plantea un dilema entre el derecho a la salud y los criterios de equidad y justicia [37]. Esta visión se contrapone al derecho a la salud y reta el discernimiento del administrador de forma cotidiana, toda vez que debe elegir la forma de asignar los recursos.

Además de promover la atención integral en el proceso salud-enfermedad en condiciones de calidad, justicia, derecho y eficiencia, el administrador en salud contemporáneo se enfrenta a problemas y dilemas éticos que devienen de la atención de situaciones que involucran procesos como: 1) la promoción de la salud, por ejemplo, la priorización de la restricción de los derechos individuales sobre los colectivos y las restricciones a la autonomía; y 2) la atención en salud, referida a los límites de la vida y la muerte, en especial las intervenciones en el ámbito de los derechos reproductivos [38,39], reflexiones que han sido promovidas por corrientes de la ética femenina y del feminismo $[38,40]$, pero también en relación con la atención de la enfermedad avanzada y la muerte digna $[41,42]$.

El administrador se encontrará con debates referidos a los conceptos de persona y de sujeto moral, a la autonomía versus el paternalismo en la asistencia clínica y de salud pública, el asunto de la vida biológica y sensitiva, pero también a la calidad misma (del buen vivir y la dignidad), los valores morales que definen la salud, y la revulnerabilización, relacionada con la discriminación social y el acceso restringido a los bienes y servicios para algunos grupos marginados en razón de su situación de salud, su edad, condición social o económica o su identidad sexual [43].

Los problemas éticos también atraviesan asuntos vinculados con las relaciones humanas, las actitudes del personal de salud frente a los pacientes, las normas y los valores institucionales, y su relación con las políticas nacionales, las pautas internacionales, lo público y lo privado, así como el papel del Estado y la sociedad.

En algunos contextos, el administrador de servicios de salud puede verse abocado a desempeñar su función en contextos de políticas adversas, movidas por el estigma, la corrupción y las acciones intimidantes de los actores violentos, que actúan en contravía del bienestar colectivo, al imponer el temor, ocasionar problemas de salud mental y restringir o al menos intimidar la acción del personal sanitario, la misión médica y al personal que administra los servicios [44,45]. Otros retos éticos resultan de los problemas asociados con la vulneración de los derechos de los pacientes y se puede observar en la Sección D de la Tabla 2.

\section{Retos éticos en investigación en salud}

Los administradores en salud pueden encontrarse en situaciones problemáticas derivadas de la falta de pertinencia o valor social o científico de los estudios que ellos realicen o administren en las organizaciones que lideran. Otros retos éticos se relacionan con el desbalance entre los intereses y propósitos de los investigadores, y la protección de las poblaciones que 
directa o indirectamente participan, lo que tiene que ver con la garantía del respeto por la integridad y la dignidad de los individuos, grupos, comunidades y territorios. Por último, es posible que el administrador se encuentre en situaciones que le planteen problemas éticos en la utilización y la difusión de los resultados, así como en la influencia que pueda producir en la toma política de decisiones y en las dinámicas sociales [46,47].

Los principales problemas y tensiones éticas en investigación están relacionados con las disparidades entre las necesidades de investigación, el papel del Estado en la financiación de la investigación, la permisividad para realizar investigaciones sin el debido valor social o sin evaluación adecuada, el no cumplimiento de los estándares nacionales o internacionales de la ética de la investigación, las faltas a la integridad científica y mala conducta en investigación.

Para cumplir adecuadamente la función de investigación, el administrador debe entender cómo está organizado el sistema nacional de ciencia y tecnología en su país, y dirimir las tensiones éticas del encuentro con los actores (investigadores, instituciones patrocinadoras, financiadores, Gobierno como formulador de las políticas $\mathrm{y}$, por supuesto, los individuos y las poblaciones involucradas). Para la realización de las investigaciones, tanto los investigadores como el administrador en salud deben tener claros los lineamientos éticos nacionales e internacionales que regulan la investigación $(48,49)$ y conocer $\mathrm{y}$ acoger las normas de integridad científica y las buenas conductas en investigación $(50,51)$. Los retos éticos en las investigaciones se pueden observar en la Sección E de la Tabla 2.

\section{Conclusión}

Los administradores de servicios de salud deben desarrollar los conocimientos y las habilidades necesarias para reflexionar y asumir una postura ética congruente con la función y los propósitos que los comprometen. No solo deben reconocer y mejorar su ethos vital, sino también desarrollar una ética profesional que les permita tomar decisiones del bien hacer en las áreas funcionales de las organizaciones (sean instituciones u organizaciones sociales), teniendo en cuenta los contextos en los que se desarrollan dichas funciones, decisiones que por supuesto dependen de las perspectivas teóricas que se acojan.

Por último, ante los retos contextuales y funcionales es necesario que el administrador en salud comprenda que, respecto a los valores de los distintos actores en conflicto, su función prioritaria es la protección de la salud, el bienestar y calidad de vida de los individuos y de las poblaciones.

\section{Declaración de autoría}

Como autora única, declaro el cumplimiento de los criterios de autoría con base en el International Committee of Medical Journal Editors, esto es, el trabajo fue concebido y elaborado por mí. Afirmo que tengo la capacidad de responder por todos los aspectos del artículo de cara a asegurar que las cuestiones relacionadas con la exactitud o integridad de cualquier parte del trabajo están adecuadamente investigadas y resueltas.

\section{Conflicto de interés}

\section{Ninguno}

\section{Fuente de financiación}

El trabajo no tuvo financiación externa, pero sí se contó con los tiempos permitidos por parte de la Universidad para la realización del mismo.

\section{Declaración de responsabilidad}

Declaro que los puntos de vista expresados son de mi responsabilidad y no representan una posición institucional.

\section{Agradecimientos}

Este trabajo se realizó en el marco de la beca otorgada por el Centro Internacional Fogarty del Instituto Nacional de Salud de Estados Unidos (NHS) para los estudios de Diploma Superior en Bioética. A la Universidad de Antioquia, por los tiempos otorgados para la realización de este trabajo.

\section{Referencias}

1. Rivera R. La ética en la administración de servicios de salud. PRHSJ [internet]. 2003 [citado 2020 ago. 11]; 22(1):35-37. Disponible en: https://bit.ly/2FiYwPP.

2. Hensley S. Underscoring ethics in healthcare management. Mod Healthc. 1997;27(8):50.

3. Cadavid G. Ética básica para profesionales. Medellín: Fundación Escuela Colombiana de mercadotecnia (ESCOLME); 1996.

4. Cely Galindo G. Ecología humana: metáfora moral reconciliadora de naturaleza y cultura [internet]. En: Cely Galindo G, editor. Bioética. Humanismo científico emergente. 3. ${ }^{\mathrm{a}}$ ed. [internet]; 2009 [citado 2017 dic. 4]. pp. 83-113. Disponible en: https://bit. ly/3gUhzxC

5. Mora Rojas RB. Propuesta de formación en ética para los estudiantes de las facultades de enfermería de Bogotá, D. C. Revista de Actualizaciones en Enfermería. Enfermería [internet]. 2010 [citado 2017 dic. 4]; 13(4):14-20. Disponible en: https://bit. ly/2U90OpY 
6. Gracia Guillén D. Fundamentación y enseñanza de la bioética. Bogotá: Editorial El Buho Ltda.; 2000.

7. Bowie NE. Un enfoque kantiano hacia la ética en los negocios. En: Frederick RE, editor. La ética en los negocios. México: Oxford University Press; 2001. pp. 310-24.

8. Hernández Escobar C, Hernández Camarena J, et al. Formación en ética y profesionalismo para las nuevas generaciones de médicos. Persona y Bioética [internet]. 2010 [citado 2017 dic. 4]; 14(1):30-9. Disponible en: https://bit.ly/2PWmoli

9. Asamblea General de la Asociación Médica Mundial (AмM). Código internacional de ética médica. Adoptado por la 3. ${ }^{\text {a }}$ Asamblea General de la AMM. Londres, Inglaterra, octubre 1949 y enmendado por la 22. ${ }^{a}$ Asamblea Médica Mundial, Sydney, Australia, agosto 1968 y la 35. ${ }^{\text {a }}$ Asamblea Médica Mundial Venecia, Italia, octubre 1983 [internet]: 1994 [citado 2021 ene. 30]. Disponible en: https:// www.wma.net/wp-content/uploads/2017/02/17a_es.pdf

10. Consejo General de Colegios Oficiales de Médicos. Código de deontología médica. Guía de ética médica. Organización Médica Colegial de España [internet]; 2011 [citado 2021 ene. 30]. Disponible en: https://www.cgcom.es/sites/default/files/codigo_deontologia_medica.pdf

11. O'Neill O. La ética kantiana. En: Singer P, editor. Compendio de ética. Madrid: Alianza [internet]; 1995 [citado 2017 dic. 4]. pp. 253-66. Disponible en: https://www.u-cursos.cl/ derecho/2015/1/D121A0103/4/material_docente/bajar\%3Fid_ material\%3D1080171

12. Beauchamp T, Childress J. Principles of biomedical ethics: Marking its fortieth anniversary. Am J Bioeth. 2019;19(11):9-12. Dor: https://doi.org/10.1080/15265161.2019.1665402

13. Hoyos Valdés D. Ética de la virtud: alcances y límites. Discusiones Filosóficas [internet]. 2007 [citado 2017 dic. 4]; 8(11):109-27. Disponible en: http://www.scielo.org.co/scielo.php?script=sci_art text\&pid=S0124-61272007000200008

14. González Esteban E. Una lectura actualizada de la ética aristotélica. La mirada de Martha Nussbaum. Quaderns de Filosofia i Ciència [internet] 2007 [citado 2017 dic. 4]; 37(1):91-100. Disponible en: https://bit.ly/36EDZwU

15. Cejudo Córdoba R. Deontología y consecuencialismo: un enfoque informacional. Crítica (Méx, D. F.) [internet]. 2010 [citado 2021 ene. 30]; 42(126):3-24. Disponible en: http:// www.scielo.org.mx/scielo.php?script=sci_arttext\&pid=S0011$15032010000300003 \& \operatorname{lng}=$ es\&nrm=iso

16. Berlinguer G. Ética de la salud. Buenos Aires: Lugar Editorial; 1996.

17. Weil $P$, Mattis M. Narrowing the gender gap in healthcare management. Healthc Exec. [internet]. 2007 [citado 2017 dic. 4]; 22 (3):22-4 26, 28-30

18. Friedman M, Friedman R. Free to Choose: A Personal Statement. Boston: Houghton Mifflin Harcourt [internet]; 1990 [citado 2017 dic. 4]. Disponible en: https://bit.ly/3709ZAp

19. Silverman HJ. Organizational ethics in healthcare organizations: Proactively managing the ethical climate to ensure organizational integrity. HEC Forum. 2000;12(3):202-15. DOI: https://doi. org/10.1023/A:1008985411047

20. Pieper A. Ética y moral: una introducción a la filosofía práctica. Crítica: Barcelona; 1991.

21. Boatright JR. La ética financiera. En: Frederick RE, editor. La ética en los negocios. México: Oxford University Press; 2001. pp. 181-96.
22. Gómez Begoña MR, Martínez Domínguez R. Los valores éticos en la responsabilidad social corporativa. Anagramas. 2016;14(28):33-50.

23. May T, Byonanebye J, Meurer J. The ethics of population health management: Collapsing the traditional boundary between patient care and public health. Popul Health Manag. 2016;20(3):167-9. https://doi.org/10.1089/pop.2016.0058

24. Swanson DL. La ética en los negocios y la economía. En: Frederick RE, editor. La ética en los negocios. México: Oxford University Press; 2001. pp. 252-64.

25. Cortina A. El estatuto de la ética aplicada. Hermenéutica crítica de las actividades humanas. Isegoría. 1996;(13):119-34. Dor: https:// doi.org/10.3989/isegoria.1996.i13.228

26. Córdoba R. Elementos para el juicio bioético. Medellín: Universidad Pontificia Boliviariana; 2005.

27. Salles A. Sobre el asco en la moralidad. Diánoia [internet]. 2009 [citado 2021 ene. 9]; 55 (64): 27-45 Disponible en: http://www.scielo.org.mx/scielo.php?script=sci_arttext\&pid $=\mathrm{S} 0185-24502010000100002$

28. Gélinier O. Etica de los negocios. Basta de ir a la deriva. México: Espasa-Calpe; 2001.

29. Klebe Treviño L. La ética en los negocios y las ciencias sociales. En: Frederick RE, editor. La ética en los negocios. México: Oxford University Press; 2001. pp. 267-74.

30. Ciulla JB. La ética en los negocios y el trabajo: preguntas para el siglo XXI. En: Frederick RE, editor. La ética en los negocios. México: Oxford University Press; 2001. pp 325-338.

31. Duska R. Derechos de los trabajadores. En: Frederick RE, editor. La ética en los negocios. México: Oxford University Press; 2001. pp 325-38.

32. Gonzalo JA, Garvey AM. Ética y enseñanza de la contabilidad (una propuesta de discusión). Contaduría Universidad de Antioquia [internet]. 2007 [citado 2017 dic. 4]; 50:11-42. Disponible en: https://revistas.udea.edu.co/index.php/cont/article/view/2120

33. Sancho F, Grané M, Olivet M. Las estrategias de participación y representatividad local y ciudadana en la Administración Sanitaria. Medicina Clínica [internet]. 2015; 145(Supl. 1):31-33. DoI: https://doi.org/10.1016/S0025-7753(15)30035-X

34. Schyve PM. Patient rights and organization ethics: The Joint Commission perspective. Bioethics Forum [internet]. 1996 [citado 2017 dic. 4]; 12(2):13-20. Disponible en: https://bit.ly/2U4zKrQ

35. Asamblea General de las Naciones Unidas. La Declaración Universal de Derechos Humanos [internet]; 1948 [citado 2017 dic. 4]. Disponible en: https://bit.ly/36C2FpR

36. unEsCo. Declaración universal sobre bioética y derechos humanos. Resoluciones. París: Organización de las Naciones Unidas para la Educación la Ciencia y la Cultura [internet]; 2007 [citado 2017 dic. 4]. Disponible en: https://bit.ly/2Gp5YJQ

37. Elster J, Herpin N. The Ethics of Medical Choice (Social Change in Western Europe). London: Bloomsbury Academic; 1995. p. 168 .

38. Luna F, Wolf AB. Challenges for assisted reproduction and secondary infertility in Latin America. Int J Fem Approaches Bioeth [internet]. 2014 [citado 2017 dic. 4]; 7(1):3-27. Disponible en: https://bit.ly/37B2QTS

39. Zegers-Hochschild F. Algunas consideraciones éticas en la práctica de la reproducción asistida en Latinoamérica. En: Casado M, Luna F, editors. Cuestiones de bioética en y desde Latinoamérica. Unesco; 2014. 
40. Baylis F. Left out in the cold: Arguments against non-medical oocyte cryopreservation. J Obstet Gynaecol Can. 2015;37(1):64-67. DOI: https://doi.org/10.1016/S1701-2163(15)30365-0

41. Naciones Unidas. Informe de la Conferencia Internacional sobre la Población y el Desarrollo [internet]; 1995 [citado 2017 dic. 4]. Disponible en: https://bit.ly/37DDjJx

42. Guerra Palmero MJ. Filosofía, bioética y estatuto del embrión. Una reconstrucción histórico-crítica del concepto de persona. Perspectivas Bioéticas [internet]. 2012 [citado 2017 dic. 4]; 32(17):45-67. Disponible en: https://bit.ly/2S3co3p

43. Kemelmajer A. Ley, religión y bioética: cuestiones álgidas en Latinoamérica. En: Casado M, Florencia L, coordinadoras. Cuestiones de bioética en y desde Latinoamérica. Madrid: Civitas; 2012. pp. 35-50.

44. Bautista Espinel GO. Tensiones bioéticas y principios aplicables en misión médica: ¿existen límites al cumplimiento del deber? Rev Latinoam Bioét [internet]. 2018;18(1):136-54. DOI: https:// doi.org/10.18359/rlbi.2987

45. Comité Internacional de la Cruz Roja. No más ataques: los pacientes, el personal de salud, los hospitales y las ambulancias \#NoSonUnObjetivo [internet]; 2017 [citado 2017 dic. 4]. Disponible en: https://bit.ly/312AZJP
46. Olivero R, Domínguez A, Malpica CC. Principios bioéticos aplicados a la investigación epidemiológica. Acta Bioeth. 2008;14(1):90-96. DOI: http://dx.doi.org/10.4067/S1726$569 \times 2008000100012$

47. Santi MF. Vulnerabilidad y ética de la investigación social: perspectivas actuales. Rev Latinoam Bioét [internet]. 2015 [citado 2017 dic. 4]; 15(2):52-73. Disponible en: http://www.scielo.org. co/scielo.php?pid $=\mathrm{S} 1657-47022015000200005 \&$ script $=$ sci abstract\&tlng=es

48. Asociación Médica Mundial. Declaración de Helsinki de la Asociación Médica Mundial [internet]. Edimburgo, Escocia [interent]; 2000 [citado 2017 dic. 4]. Disponible en: https://bit.ly/2Opg2DR

49. Lopera MM. Revisión comentada de la legislación colombiana en ética de la investigación en salud Biomédica. 2017;37(4):577-89. DOI: https://doi.org/10.7705/biomedica.v37i4.3333

50. Organización Mundial de la Salud, Organización Panamericana de la Salud. Caso 64. Finalmente, ¿de quién es la idea? En: Cash R, Wikler D, et al., editores. Estudios de casos sobre ética de la investigación internacional en salud. Washington: Organización Mundial de la Salud; 2014.

51. Fanelli D. How many scientists fabricate and falsify research? A systematic review and meta-analysis of survey data. PloS One. 2009;4(5):e5738. DoI: https://doi.org/10.1371/journal. pone. 0005738

Esta obra se distribuye bajo una Licencia Creative Commons Atribución-NoComercial-CompartirIgual 4.0 Internacional 